\title{
REVIEW
}

\section{Guidelines for managing acute gastroenteritis based on a systematic review of published research}

\author{
M S Murphy
}

This paper is intended to provide evidencebased recommendations about the assessment and clinical management of infants and children with acute gastroenteritis. These guidelines were derived from a systematic review of published research. The diagnosis of gastroenteritis is not addressed; this is often presumptive and is based on a history of acute diarrhoea in the absence of other likely explanations. Microbiological investigation is not necessary in every case, but may be important in patients who require admission to hospital, in those who have bloody or mucoid diarrhoea suggesting colitis, in high risk patients such as those with an immune deficiency, and in cases where there is diagnostic uncertainty. Clinicians should apply general medical knowledge and clinical judgment in using these guidelines.

\section{Scope of guidelines}

The topics addressed are: assessment of the risk of dehydration; assessment of the degree of dehydration; oral rehydration therapy (ORT); strategies for rehydration and maintenance of hydration; management of hypernatraemic dehydration; nutritional management during and after the illness; and the role of pharmacological agents including antidiarrhoeals and antimicrobials.

\section{Systematic review: search strategy and evaluation of the evidence}

The search was performed using the MEDLINE and Cinahl databases, and covered the years 1966-97. Some relevant articles were also identified from the references cited in publications identified from these databases. The search was limited to studies of human subjects published in English. Subject headings employed were: "gastroenteritis", "diarrhoea", "rehydration solutions", "dehydration", and "hypernatraemia". Textword searches were also done using the terms "infectious diarrh\$", "oral rehydration solution\$", and "hypernatr\$ dehydration". For each topic the terms "review", "metaanalysis", "randomised controlled trial", "cohort study", and "case control study" were applied. The Cochrane Library database of systematic reviews was searched under subject headings. Evidence from the medical literature and the strength of the recommendations given were then categorised according to a previously described scheme (table 1 ). ${ }^{1}$

\section{Assessment of hydration}

The risk of dehydration or, if already established, the severity of dehydration, can be assessed from a patient's clinical history and physical examination.

RISK FACTORS FOR DEHYDRATION

The risk of dehydration in children is related to age. ${ }^{2}$ Young infants have an increased surface area:body volume ratio resulting in increased insensible fluid losses. They receive milk as the main source of nutrition; this constitutes a large osmotic load that may promote an osmotic diarrhoea, and a large protein load resulting in a high renal solute load. Finally, infants have an inherent tendency to more severe vomiting and diarrhoea compared with older children and adults.

It is logical to assume that severe symptoms, including frequent vomiting and watery diarrhoea, would predict an increased risk of dehydration. Retrospective case-control studies from developing countries have confirmed this. ${ }^{34}$ Studies from the Indian subcontinent have identified failure to give oral rehydration solution (ORS) and discontinuation of breast feeding during the illness as the greatest risk factors for dehydration. ${ }^{4}$ In those studies other variables contributing to risk included age ( $<12$ months), frequent stools ( $>$ eight/ day), vomiting ( $>$ twice/day), and severe undernutrition. In studies from South America of children $<2$ years old with acute diarrhoea, the use of bottle feeding rather than breast feeding was identified as an independent risk factor for dehydration. ${ }^{67}$ In a study on the significance of specific pathogens, Vibrio cholerae was associated with a high risk of dehydration, while other pathogens including rotavirus, Campylobacter jejuni, and enterotoxigenic Escherichia coli were comparable with one another with respect to risk of dehydration. ${ }^{8}$

\section{Table 1 Categories of evidence and recommendations}

Evidence categories

(I) Based on well designed randomised controlled trials, meta-analyses, or systematic reviews

(II) Based on well designed cohort or case-control studies (III) Based on uncontrolled studies or consensus

Strength of recommendation categories

(A) Directly based on category I evidence

(B) Directly based on category II evidence or extrapolated from category I evidence

(C) Directly based on category III evidence or extrapolated from category I or II evidence 
Table 2 Composition (mmol/l) of available oral rehydration solution preparations

\begin{tabular}{lcccccc}
\hline & $\mathrm{Na}^{+}$ & $\mathrm{K}^{+}$ & $\mathrm{Cl}^{-}$ & $\mathrm{HCO3}^{-}$ & Citrate & Glucose \\
\hline Diocalm Junior (Smith Kline & & & & & & \\
$\quad$ Beecham) & 60 & 20 & 50 & - & 10 & 111 \\
Dioralyte (Rhone Poulenc Rorer) & 60 & 20 & 60 & - & 10 & 90 \\
Dioralyte (tabs) & 60 & 25 & 45 & - & 20 & 90 \\
Electrolade (Nicholas) & 50 & 20 & 40 & 30 & - & 111 \\
Gluco-lyte (Cupal) & 35 & 20 & 37 & 18 & - & 200 \\
Rapolyte (Janssen) & 60 & 20 & 50 & - & 10 & 111 \\
Rehidrat (Searle) & 50 & 20 & 50 & 20 & 9 & 91 (+94 sucrose) \\
WHO-ORS & 90 & 20 & 80 & - & 10 & 111 \\
\hline
\end{tabular}

^Effervescent tablets; other products are provided as sachets of powder to dissolve in water.

CLINICAL ASSESSMENT OF HYDRATION

The severity of dehydration is usefully expressed in terms of weight loss as a percentage of total body weight. If a recent weight record is available (for example, from the parent held medical record) dehydration can be estimated with some accuracy.

The severity of dehydration can also be determined using certain specific clinical criteria. In a prospective cohort study of subjects between 3 months and 18 months of age, multiple regression analysis selected "prolonged skinfold", dry oral mucosa, sunken eyes, and altered neurological status as the clinical signs that best correlated with dehydration as determined by pre-rehydration and postrehydration weights. ${ }^{9}$ In that study, those subjectively judged to be "mildly dehydrated" showed weight gains of 3.6-3.9\%, "moderate dehydration" was associated with weight gains of 4.9-5.3\%, and "severe dehydration" with weight gains of $9.5-9.8 \%$.

Capillary refill time ( $>2$ seconds) has been proposed as a useful indicator of dehydration. ${ }^{10}$ This technique lacks sensitivity and specificity, but a normal capillary refill time is very unlikely with severe dehydration. ${ }^{11} 12$

\section{Recommendations on assessment of hydration}

- Assess risk of dehydration on the basis of age (highest in young infants) and frequency of watery stools and vomiting [II,B]

- Assess presence/severity of dehydration on the basis of recent weight loss (if possible) and clinical examination. Signs of proved value in assessing dehydration include "prolonged skinfold", dry oral mucosa, sunken eyes, and altered neurological status [I,A].

\section{Fluid management}

In children with clinical evidence of dehydration, biochemical investigations including serum electrolytes, urea, and creatine and assessment of acid/base status may be helpful. Irrespective of the serum electrolyte concentrations, however, dehydration from gastroenteritis is invariably associated with total body deficits of sodium and chloride. In addition, there is often significant potassium depletion and acidosis. Hyponatraemia and hypernatraemia are simply indicative of the relative losses of water and sodium. The rehydration fluid should replace both water and electrolyte losses. In many cases an initial phase of rehydration is necessary, followed by a fluid maintenance phase aimed at preventing the recurrence of dehydration (fig 1).
ORAL REHYDRATION THERAPY

In all but the most seriously ill patients rehydration is possible using ORT. The effectiveness of ORT was first proved 30 years ago in major clinical studies undertaken during cholera epidemics in Bangladesh. ${ }^{13} 14$ These studies were possible after the discovery in the 1960 s that intestinal water absorption was mediated by an active transport process in which sodium and glucose were cotransported in an equimolar ratio. Studies in the laboratory animal showed that glucose stimulated intestinal sodium absorption. ${ }^{15}$ Studies in human subjects confirmed this observation in man, and showed that the sodium-glucose cotransporter continued to function in patients with cholera. ${ }^{16-19}$ Subsequently, controlled studies showed the effectiveness of ORT in infants and children with non-cholera diarrhoea. ${ }^{20} 21$

The use of ORT in the management of gastroenteritis in the UK was associated with a dramatic fall in mortality, from 300 deaths annually in the late 1970 s to about 25 in the late $1980 \mathrm{~s}^{22}$ Hypernatraemic dehydration, a major cause of mortality in acute gastroenteritis, also became much less common. ${ }^{23}$

COMPOSITION OF ORAL REHYDRATION SOLUTIONS A range of ORS products are currently available, and these vary markedly in their sodium and glucose concentrations (table 2). Although these are generally effective in the treatment and prevention of dehydration, there has been controversy about the ideal composition for ORS. ${ }^{1424}$

\section{Sodium}

In the 1970 s the World Health Organisation (WHO) adopted a glucose-electrolyte solution (WHO-ORS) containing $90 \mathrm{mmol} / \mathrm{l}$ of sodium, and this was promoted for worldwide use. This solution was originally evaluated in adults with cholera or cholera-like (toxigenic) diarrhoea, the category of patients for whom it was primarily designed. Later, however, its use was extended to children with non-toxigenic diarrhoea, including rotavirus gastroenteritis. ${ }^{25}$ In the underdeveloped world, diarrhoeal disease is often associated with large stool sodium losses. $^{24}$ In patients in Western countries, sodium loss is generally less severe, and so there has been concern about the risk of hypernatraemia with WHO-ORS, especially in infants $<3$ months of age. ${ }^{26}{ }^{27}$ Moreover, controlled clinical trials in infants $<3$ months and in older children have shown that an ORS with a sodium concentration in the range 50-60 $\mathrm{mmol} / \mathrm{l}$ is safe and effective in the treatment and prevention of dehydration. ${ }^{28-33}$ The European Society for Paediatric Gastroenterology and Nutrition (ESPGAN) published guidelines based on these studies, recommending a sodium concentration of $60 \mathrm{mmol} / 1$ for European children. ${ }^{34}$

\section{Glucose}

The ideal carbohydrate concentration in ORS must be related to the sodium concentration. The WHO has recommended a glucose:sodium ratio of less than $1.4: 1{ }^{14}$ Hyperosmolar 


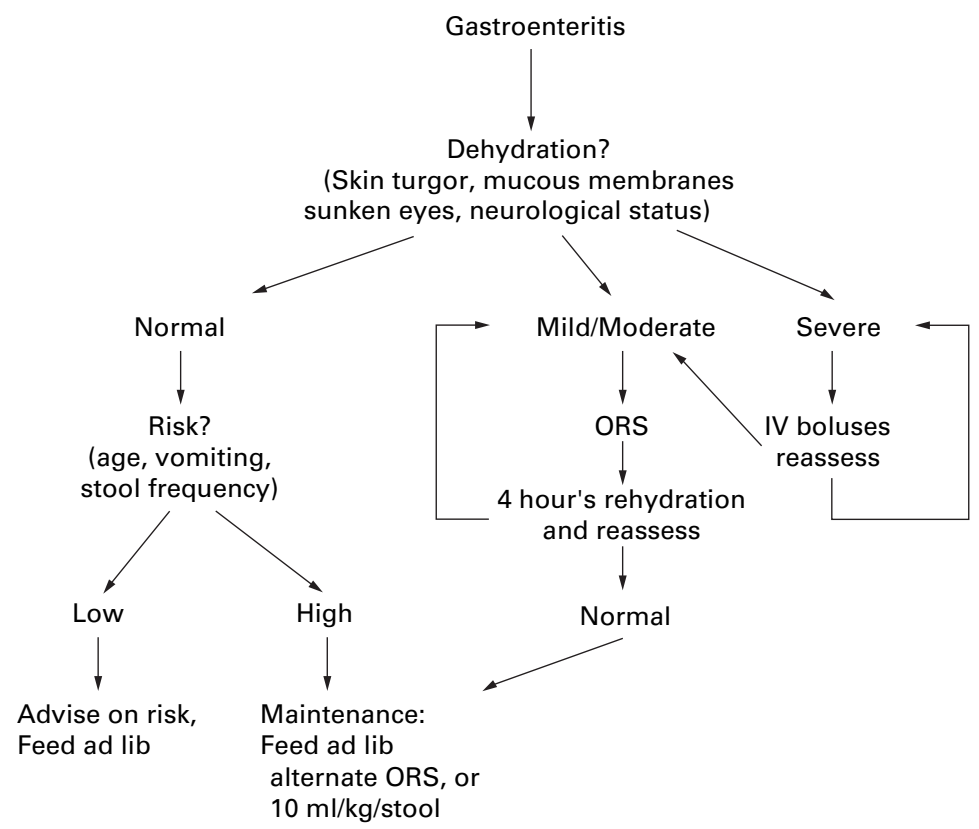

Figure 1 Management of hydration in gastroenteritis.

ORS containing excessive amounts of carbohydrate could induce osmotic diarrhoea as a result of carbohydrate malabsorption, and the associated water loss would increase the risk of hypernatraemia. ESPGAN has therefore recommended the use of a hypo-osmolar ORS for European children. ${ }^{34}$

Glucose may be provided as monosaccharide or as a complex carbohydrate (for example, glucose polymer or starch). Complex carbohydrates have the theoretical advantage of forming solutions of reduced osmolality, although they require digestion before absorption. In underdeveloped countries, cereal based ORS has been successfully employed. ${ }^{35} \mathrm{~A}$ recent meta-analysis of 13 clinical trials examined the effect of rice based ORS on stool output and duration of diarrhoea; there appeared to be a worthwhile benefit in patients with cholera, but the effect in children with acute non-cholera diarrhoea was uncertain. ${ }^{36}$ Appropriately therefore most solutions currently in use contain glucose as monosaccharide (table 2).

Potassium, bicarbonate, and base precursors Most ORS products contain $20 \mathrm{mmol} / 1$ of potassium, and this appears sufficient to prevent hypokalaemia despite individual variation in stool potassium losses. ${ }^{24}$ Most contain bicarbonate, or more often a stable baseprecursor such as acetate, lactate, or citrate. These constituents were originally included to correct the acidosis that may accompany dehydration, and to promote water and sodium absorption. In fact there is no evidence that inclusion of base is necessary or beneficial. ${ }^{24}$

REHYDRATION

In the past many regimens aimed at gradual rehydration over 24 hours or longer, but this approach was not evidence based. It seems both illogical and potentially disadvantageous to delay the process of recovery in these children by prolonging the rehydration process. Nowadays most authorities recommend rapid rehydration over a three or four hour period. $^{2}{ }^{13} 14$

The degree of dehydration is estimated as outlined above and expressed as percentage of body weight. The fluid deficit can then be calculated: thus, an estimated 5\% dehydration would be treated by giving $50 \mathrm{ml} / \mathrm{kg}$ of replacement fluid. ORS may be given by bottle, cup, or spoon as appropriate, and frequent administration may be necessary to repair the deficit within four hours. Most dehydrated children are thirsty and will take fluids readily, but some seriously ill children may require ORS given via an enteral tube. Rehydration should be done under medical supervision, and the state of hydration should be reassessed during rehydration and at the end of the four hour rehydration period. If the patient is still dehydrated then the residual deficit is again estimated and the rehydration process is continued. If children vomit during the process of rehydration, more ORS is immediately given.

Most authorities recommend that children with signs of shock (inadequate perfusion of vital organs) should receive intravenous rehydration initially. ${ }^{214}$ Although oral rehydration is quite possible in such cases, the intravenous route helps to guarantee rapid rehydration in these critically ill patients.

In cases of hypernatraemic dehydration (serum sodium $>150 \mathrm{mmol} / \mathrm{l}$ ) slower fluid replacement over 12 hours has been recommended to reduce the risk of seizures ("slow ORT"). ${ }^{37}$ There is a consensus that the use of ORT can in itself reduce the risk of seizures during rehydration. ${ }^{14}$ In one report none of 34 infants with hypernatraemic dehydration suffered seizures when rehydration was repaired with WHO-ORS over 12 hours. ${ }^{38}$ In the largest published controlled trial of intravenous versus oral rehydration, 470 children under 18 months of age, all with severe gastroenteritis, were randomly assigned to receive either ORS or intravenous fluid. ${ }^{39}$ Of 34 hypernatraemic patients in the ORT group, $2(6 \%)$ developed seizures compared with 6 of $24(25 \%)$ in the group given intravenous treatment. These studies are reassuring, although it may be significant that WHO-ORS (sodium 90 $\mathrm{mmol} / \mathrm{l}$ ) was used, as opposed to the ORS currently recommended in Europe (sodium 60 $\mathrm{mmol} / \mathrm{l})$. It is therefore important that the serum sodium concentration be closely monitored during rehydration because rapid reductions are associated with an increased risk of cerebral oedema and convulsions.

\section{MAINTENANCE TREATMENT}

Various strategies have been recommended to prevent dehydration and to prevent the recurrence of dehydration from ongoing fluid losses when rehydration is complete. ${ }^{2}{ }^{13} 40$ Children require their normal maintenance fluid, and this can be calculated from body weight. A useful method is to provide $100 \mathrm{ml} / \mathrm{kg} /$ day for the first $10 \mathrm{~kg}$ of body weight, $50 \mathrm{ml} / \mathrm{kg} /$ day for the next $10 \mathrm{~kg}$, and $25 \mathrm{ml} / \mathrm{kg} /$ day thereafter. ${ }^{2} \mathrm{In}$ practice, fluids are offered ad libitum and in 


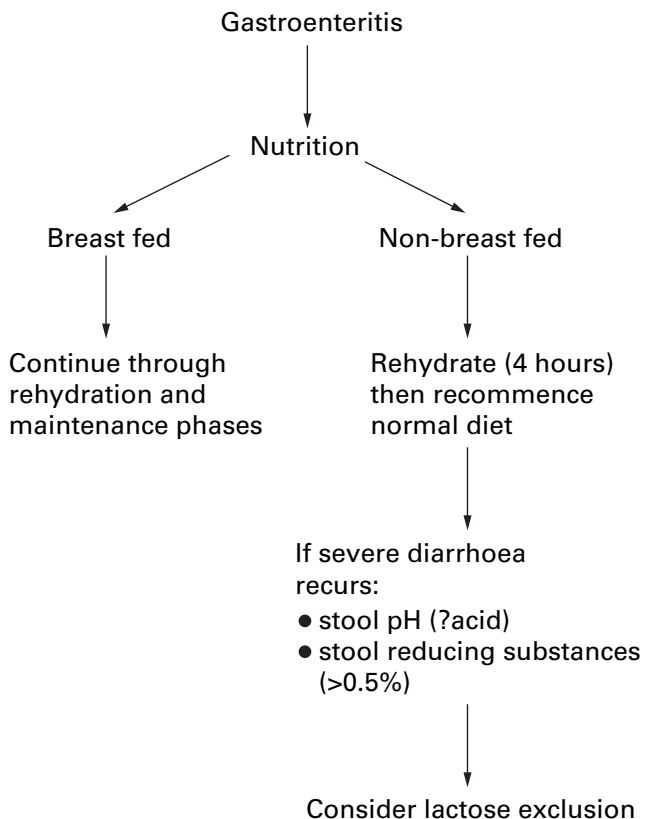

Figure 2 Management of feeding in gastroenteritis.

almost all cases children will meet or exceed such calculated "maintenance requirements". Maintenance fluids can be given as breast milk, formula, or other fluids appropriate for age.

In addition to maintenance requirement, however, continuing losses due to persistent diarrhoea or vomiting should be replaced with extra feeds of ORS. One strategy is to alternate freely normal feeds with ORS feeds. ${ }^{2}$ An alternative is to give approximately $10 \mathrm{ml} / \mathrm{kg}$ for each diarrhoeal stool passed. ${ }^{14}$

Recommendations on fluid management

- An ORS containing sodium $60 \mathrm{mmol} / \mathrm{l}$, glucose $90 \mathrm{mmol} / 1$, potassium $20 \mathrm{mmol} / 1$, and citrate $10 \mathrm{mmol} / \mathrm{l}$ with an low osmolality of $240 \mathrm{mmol} / 1$ is safe and effective for the prevention and treatment of dehydration in European children with acute gastroenteritis [I,A]

- In the vast majority of cases rehydration should be carried out using ORT [I,A]

- Rehydration should normally be completed over a three to four hour period [II,B]

(a) "Mild" dehydration (3-5\%): 30-50 ml/kg as ORT over three to four hours

(b) "Moderate" dehydration (5-10\%): 50$100 \mathrm{ml} / \mathrm{kg}$ as ORT over three to four hours

(c) "Severe" dehydration $(10 \%+): 100-150$ $\mathrm{ml} / \mathrm{kg}$ as ORT over three to four hours

(d) Reassess hydration immediately after giving the estimated deficit

- Severe dehydration with signs of shock: 20 $\mathrm{ml} / \mathrm{kg}$ boluses of normal saline intravenously [III,C]

- When organ perfusion is restored begin ORT.

In hypernatraemic dehydration, ORT is safer than intravenous rehydration [II,B]

- In hypernatraemic dehydration use "slow ORT", aiming to complete rehydration over 12 hours, and monitor serum sodium to avoid a rapid reduction [III,C]
- To prevent primary dehydration or recurrence of dehydration, allow unrestricted fluids, and in high risk cases either (a) alternate normal drinks (for example, milk or water) with ORS [III,C], or (b) give normal drinks and $10 \mathrm{ml} / \mathrm{kg}$ ORS after each watery stool [III,C].

\section{Nutritional management}

Until recently it was considered that the early reintroduction of feeds after acute gastroenteritis risked exacerbating the illness, causing protracted diarrhoea. Children were routinely starved for 24 hours or even longer ${ }^{41}$ Evidence has now emerged, however, favouring the early reintroduction of feeds (fig 2).

Firstly, there is indirect evidence to support this strategy based on studies revealing the positive effects of luminal nutrition on mucosal growth and regeneration. Early refeeding was shown to reduce the abnormal increase in intestinal permeability that occurs in acute gastroenteritis. ${ }^{42}$ Increased permeability is considered to indicate a loss of mucosal integrity. Early refeeding may also enhance enterocyte regeneration, and may promote recovery of the brush border membrane disaccharidase. ${ }^{43}{ }^{43 \mathrm{~A}}$

Many studies have now indicated that there is no advantage to the practice of "regrading" feeds - that is, gradually increasing the feed concentration during the recovery phase after gastroenteritis. ${ }^{44-49}$ In malnourished children, early refeeding has been associated with significant nutritional advantages. ${ }^{50}$ In a recent multicentre European study, 230 weaned children $<3$ years of age with acute gastroenteritis were randomly assigned to "early refeeding" or "late refeeding". ${ }^{51}$ These children were not generally malnourished before the onset of their illness. Oral rehydration was carried out over four hours. The "early refeeding" group then received a normal diet without further delay. The "late refeeding" group received maintenance ORS for a further 20 hours, and then restarted a normal diet. Both groups were offered ORS $10 \mathrm{ml} / \mathrm{kg}$ after each watery stool. Breast fed infants continued to feed during the rehydration and maintenance phases. There was no difference between the two groups in the incidence of vomiting or watery stools on days 1 to 5 , and weight gain was similar in both groups on days 5 and 14 .

Transient lactase deficiency is common, particularly after rotavirus gastroenteritis. Occasionally it persists, and lactose intolerance may be a cause of post-gastroenteritis diarrhoea. ${ }^{52}$ In Europe this appears to have become a rather uncommon clinical problem. ${ }^{53}$ Moreover, a meta-analysis of clinical trials has indicated that a lactose free diet is rarely necessary after acute gastroenteritis. ${ }^{54}$ In a case-control study of Bangladeshi children $<3$ years, multivariate analysis using a logistic regression model showed that discontinuation of breast feeding during the illness was associated with a fivefold increase in the incidence of dehydration. ${ }^{5}$ There is some evidence that continued breast feeding may actually reduce stool output. ${ }^{56}$

Based on these studies, ESPGAN recently issued guidelines with regard to feeding in 
childhood gastroenteritis. ${ }^{57}$ The recommendations were for oral rehydration over a period of three to four hours, followed by immediate reintroduction of normal feeds thereafter. It was also recommended that breast feeding should be continued throughout the rehydration and maintenance phases of treatment. It was considered that lactose free formulas were rarely necessary. Although persistent lactose intolerance is now uncommon, it was suggested that if persistent diarrhea occurred after the reintroduction of milk, stool $\mathrm{pH}$ and stool reducing substances should be measured, and a lactose free formula should be considered if the stool was acid and contained more than $0.5 \%$ reducing substances. ${ }^{43 \mathrm{~A}}$

Recently we reported a series of infants in whom the administration of a glucose polymer formula resulted in severe protracted diarrhoea. $^{58}$ These infants were eventually found to have congenital sucrase-isomaltase deficiency. Unfortunately, in such cases the diarrhoea is likely to be attributed to postgastroenteritis syndrome. Congenital sucraseisomaltase deficiency is not rare, and the inability of these infants to digest glucose polymer had not previously been appreciated. ${ }^{59}$

\section{Recommendations on nutritional management}

- Breast feeding should continue through rehydration and maintenance phases of treatment [II,C]

- Formula feeds should be restarted after completion of rehydration [I,A]

- If there is persistent diarrhoea after reintroduction of feeds, evidence for lactose intolerance should be sought. If the stool $\mathrm{pH}$ is acid and contains more than $0.5 \%$ reducing substances a lactose free formula should be considered [III,C].

\section{Pharmacotherapy}

ANTIDIARRHOEAL AGENTS

In the past antidiarrhoeal drugs were often employed in the treatment of acute gastroenteritis, but with little evidence of benefit. ${ }^{60}$ Bismuth subsalicylate has antisecretory and bactericidal properties, and it may have some effect on the clinical symptoms. ${ }^{61}$ There is no evidence that other agents such as cholestyramine, loperamide, kaolin, pectin, and diphenoxylate have an effect. ${ }^{62-65}$ Nowadays, none of these drugs is considered to have a role in the treatment of gastroenteritis in children, and it is possible that their use may have adverse consequences. ${ }^{60}$

ANTIMICROBIAL AGENTS

Although $C$ jejuni gastroenteritis is often a mild and self limiting illness, one randomised controlled trial indicated that if erythromycin was started at first presentation, before stool culture results were available, the clinical course of the illness was shortened. ${ }^{66}$ Several other randomised trials in which erythromycin was started after isolation of the organism showed a shortened period of bacterial excretion, but no effect on the clinical course of the illness. ${ }^{67}{ }^{68} \mathrm{~A}$ single randomised controlled trial of treatment in children with $Y$ enterocolitica using trimethoprim/sulfamethoxazole failed to show any useful benefit. ${ }^{69}$ The role of antibiotics in the treatment of $E$ coli associated acute gastroenteritis in the UK is unclear. ${ }^{70}$ Nontyphoidal salmonella gastroenteritis is usually self limiting, and studies have failed to show any benefit from antibiotic treatment. ${ }^{70}$ In one study, ampicillin or amoxycillin treatment appeared to be associated with prolonged salmonella excretion in children. ${ }^{70}$ It has been suggested that antibiotic treatment may be indicated in the very young, in immunocompromised patients, and in those who are systemically ill. ${ }^{70}$ There is clear evidence that antibiotic treatment is worthwhile in patients with shigella dysentery, in whom it shortens the clinical illness and the duration of pathogen excretion. ${ }^{70}$

\section{Recommendations regarding pharmacotherapy}

- Infants and children with gastroenteritis should not be treated with antidiarrhoeal agents [I,A]

- Most bacterial gastroenteritis does not require or benefit from antibiotic treatment $[\mathrm{I}, \mathrm{A}]$

- Antibiotic treatment may be indicated for salmonella gastroenteritis in the very young, in immunocompromised patients, and in those who are systemically ill [III,C]

- Patients with shigella dysentery should receive antibiotic treatment [I,A].

1 Eccles M, Clapp Z, Grimshaw J, et al. North of England evidence based guidelines development project: methods of guideline development. BMF 1996;312:760-2.

2 Goepp JG, Hirschhorn B. Fluid therapy of diarrhoea. Industrialized countries. In: Walker WA, Durie PR, Hamilton JR, Walker-Smith JA, Watkins JB, eds. Pediatric gastrointestinal disease: pathophysiology, diagnosis, management. Philadelphia: Decker BC, 1991:1567-76.

3 Lulseged S. Predictors of moderate to severe dehydration in acute diarrhoeal disease: a case control study. Ethiopian Medical fournal 1992;30:69-78.

4 Bhattacharya SK, Bhattacharya MK, Manna B, et al. Risk factors for development of diarrhoea in young children: a case control study. Acta Paediatrica 1995;84:160-4

5 Faruque AS, Mahalanabis D, Islam A, Hoque SS, Hasnat A Breast feeding and oral rehydration at home during diarrhoea to prevent dehydration. Arch Dis Child 1992;67: $1027-9$

6 Victoria CG, Fuchs SC, Kirkwood BR, Lombardi C, Barros FC. Bull World Health Organ 1992;70:467-75.

7 Fuchs SC, Victoria CG, Martines J. Case-control study of risk of dehydrating diarrhoea in infants in vulnerable period after full weaning. BMF 1996;313:391-4.

8 Faruque AS, Mahalanabis D, Islam A, Hoque SS, Hasnat A. Am F Trop Med Hygiene 1993;49:93-100.

9 Duggan C, Refat M, Hashem M, Wolff M, Fayad I, Santosham $M$. How valid are clinical signs of dehydration in infants? F Pediatr Gastroenterol Nutr 1996;22:56-61.

10 Saavedra JM, Harris GD, Li S, Finberg L. Capillary refilling (skin turgor) in the assessment of dehydration. Am $\mathcal{F} \mathrm{Dis}$ Child 1991;145:296-8.

11 Gorelick MH, Shaw KN, Baker MD. Effect of ambient temperature on capillary refill in healthy children. Pediatrics perature on capillary

12 Baraff LJ. Capillary refill: is it a useful clinical sign? [editorial] Pediatrics 1993;92:723-4

13 Mahalanabis D, Snyder JD. Fluid and dietary therapy of diarrhoea. In: Walker WA, Durie PR, Hamilton JR, WalkerSmith JA, Watkins JB, eds. Pediatric gastrointestinal disease: pathophysiology, diagnosis, management. Philadelphia: Decker BC, 1996:1843-50

14 Meyer A. Fluid and electrolyte therapy for children. Current Opinion in Pediatrics 1994;6:303-9.

15 Schultz SG, Zalusky R. Transport in isolated rabbit ileum: II. Interaction between active sodium and active sugar transport. F Gen Physiol 1964;47:1043.

16 Philips RA. Water and electrolyte losses in cholera. Fed Proc 1964;23:705-12.

17 Malawar SJ, Ewton M, Fordtran JS. Interrelationship between jejunal absorption of sodium, glucose and water in man. F Clin Invest 1966;44:1072. 
18 Hirschorn N, Kinzie J Sachar D, Northrup R, Taylor J, Ahmad S. Decrease in net stool output in cholera during Engl f Med 1968;279:176-82.

19 Sladen GE, Dawson AM. Inter-relationships between the absorptions of glucose, sodium and water by the normal human jejunum. Clin Sci 1969;36:119-32.

20 Hirschorn N, Cash RA, Woodward WB, Spivey GH. Oral fluid therapy of Apache children with acute infectious diarrhoea. Lancet 1971 ;ii: 15

21 Nalin DR, Levine MM, Mata L, et al. Oral rehydration and maintenance of children with rotavirus and bacterial diarrhoea.Bull World Health Organ 1979;57:453-9.

22 Walker-Smith JA. Management of infantile gastroenteritis [editorial]. Arch Dis Child 1990;65:917-18.

23 Sunderland R, Emery JL. Apparent disappearance of hypernatraemic dehydration from infant deaths in Sheffield. BMF 1979; ii:575-6.

24 Walker-Smith JA. Advances in the management of gastroenteritis in children. Br 7 Hosp Med 1992;48:582-5.

25 Sack DA, Chowdbury A, Euso FA. Oral rehydration in rotavirus diarrhoea: a double blind comparison of sucrose with glucose electrolyte solution. Lancet 1978;ii:80-2.

26 Abdalla S, Helmy N, El Essaily M, Nassar S, Hirschorn N. Oral rehydration for the low birth weight baby with diarrhoea. Lancet 1984;ii:818-19.

27 Bhargarva SK, Sachder HPS, Das Gupta B, Danal TS, Singh HP, Mohan $M$. Oral rehydration of neonates and young infants with dehydrating diarrhoea: comparison of low and standard sodium content in oral rehydration solutions. F Pediatr Gastroenterol Nutr 1984;3:500-4

28 Nalin DR, Hanland E, Ramlal A, et al. Comparison of low and high sodium and potassium content in oral rehydration solutions. F Pediatr 1980;97:848-53.

29 Santosham M, Daum RS, Dillman L, et al. Oral rehydration therapy of infantile diarrhoea. A controlled study of well-nourished children hospitalized in the United States and Panama. N Engl f Med 1982;306:1070-6.

30 Pizzaro D, Posada G, Villariceucis N, Mohs E, Levine MM Oral rehydration in hypernatraemic and hyponatraemic Oral rehydration in hypernatraemic and hyponatraemic trolyte solution. Am F Dis Child 1983;137:730-4.

31 Isolauri E, Vesikari T. Oral rehydration, rapid feeding and cholestyramine for treatment of acute diarrhoea. 7 Pediatr Gastroenterol Nutr 1985;3:252-6.

32 Bhargarva S, Sachder HPS, Das Gupta B, Mohan M, Singh HP, Danal TS. Oral therapy of neonates and young infant with dehydrating diarrhoea: composition of low and standard sodium in oral rehydration solutions. $\mathcal{F}$ Pediat Gastroenterol Nutr 1986;6:416-22.

33 International Study Group on reduced-osmolality ORS solutions. Multicentre evaluation of reduced-osmolarity oral rehydration salts solution. Lancet 1995;345:282-5.

34 Booth I, Cunha Ferreira R, Desjeux JF, et al. Recommendations for composition of oral rehydration solutions from the children of Europe. Report of an ESPGAN working group. 7 Pediatr Gastroenterol Nutr 1992;14:113-15.

35 Bhan MK, Mahalanabis D, Fontaine O, Pierce NF. Clinical trials of improved oral rehydration salt formulations: a trials of improved oral rehydration salt form

36 Gore SM, Fontaine O, Pierce NF. Impact of rice based oral rehydration solution on stool output and duration of diarrhoea: meta-analysis of 13 clinical trials. BMF 1992 304:287-91.

37 Pizarro D, Posada G, Levine M. Hypernatremic diarrhoeal dehydration treated with "slow" (12-hour) oral rehydration therapy: a preliminary report. F Pediatr 1984;104:316-9.

38 Pizarro D, Posada G, Levine M. Hypernatraemic diarrhoeal dehydration treated with "slow" (12-hour) oral rehydration therapy: a preliminary report. $\mathcal{F}$ Pediatr 1984;104:316-9.

39 Sharifi J, Ghavami F, Nowrouzi Z, et al. Oral versus intravenous rehydration therapy

40 Goepp JG, Katz SA. Oral rehydration therapy. Am Fam Physician 1993;47:843-51.

41 Goodburn E, Mattosinho S, Mongi P, Waterson T. Management of childhood diarrhoea by pharmacists. Is Britain lagment of childhood diarrhoea by pharmacists. Is Britain

42 Isolauri $\mathrm{E}$, Juntunen $\mathrm{M}$, Wiren $\mathrm{S}$, et al. Intestinal permeability changes in acute gastroenteritis: effects of clinical factors and nutritional management. $\mathcal{F}$ Pediatr Gastroenterol Nutr 1989;8:466-73.

43 Levine GM, Deren JJ, Steiger E, Zinn R. Role of oral intake in maintenance of gut mass and disaccharidase activity. Gastroenterology 1974;67:972-82.

43A Newton T, Murphy MS, Booth IW. Protracted diarrhoea induced by glucose polymer in infants with unrecognized congenital sucrase/isomaltase deficiency. F Pediatr 1996, 128:753-6.
44 Rees L, Brook CGD. Gradual reintroduction of full strength milk after acute gastroenteritis in children. Lancet 1979;ii: $770-1$.

45 Dugdale A, Lovell S, Gibbs V, Ball D. Refeeding after acute gastroenteritis: a controlled study. Arch Dis Child 1982;57: $76-9$

46 Placzec M, Walker-Smith JA. Comparison of two feeding regimens following acute gastroenter

47 Isolauri E, Vesikari T, Saha P, Viander M. Milk versus no milk in rapid refeeding after acute gastroenteritis. $\mathcal{F}$ Pediatr Gastroenterol 1986;5:254-61.

48 Vesikari T, Isolauri E. Oral rehydration, rapid feeding and cholestyramine for treatment of acute diarrhea. 7 Pediatr Gastroenterol Nutr 1986;5:254-61.

49 Hoghton MAR, Mittal NK, Mahdi G, Sandhu BK. Continuous modified feeding in acute gastroenteritis. $\mathcal{F}$ Gen Practice 1996;46:173-5.

50 Brown KH, Gastanaduy AS, Saavedra JM, et al. Effect of continued oral feeding on clinical and nutritional outcomes of acute diarrhoea in children. F Pediatr 1988;112:191-200.

51 Sandhu BK, Isolauri E, Walker-Smith JA, et al. Early feeding in childhood gastroenteritis. A multicentre study on behalf of the European Society of Paediatric Gastroenterology and Nutrition working group on acute diarrhoea. $\mathcal{F}$ Pediatr Gastroenterol Nutr 1997;24:522-7.

52 Burke V, Kerry KR, Anderson E. The relationship of dietary lactose to refractory diarrhoea in infancy. Australian Paediatrics fournal $1965 ; 1: 147-54$

53 What has happened to carbohydrate intolerance following gastroenteritis? Lancet 1987;i.23-4.

54 Brown KH, Peerson JM, Fontaine O. Use of nonhuman milks in the dietary management of young children with acute diarrhoea: a meta-analysis of clinical trials. Pediatrics 1994;93:17-27.

55 Khin-Maung U, Wai N, Myo-Khin, Mu-Mu-Khin, Tin U, Thane-Toe. Effect on clinical outcome of breast feeding during acute diarrhoea. $B M 7$ 1 $985 ; 290: 587-9$.

56 Walker-Smith JA, Sandhu BK, Isolauri E, et al. Recommendations for feeding in childhood gastroenteritis. Medical position paper. Guidelines prepared by the ESPGAN working group on acute diarrhoea. 7 Pediatr Gastroenterol Nutr 1997;24:619-20.

57 Penny ME, Paredes PO, Brown KH. Clinical and nutritional consequences of lactose feeding during persistent consequences of lactose feeding during p

58 Treem WR. Congenital sucrase-isomaltase deficiency. $f$ Pediatr Gastroenterol Nutr 1995;21:1-14.

59 Du Pont HL. Nonfluid therapy and selected chemoprophylaxis of acute diarrhea. Am $\mathcal{F}$ Med 1985;78:81-90.

60 Soriano-Brucher HE, Avendano P, O'Ryan M, Soriano HA. Use of bismuth subsalicylate in acute diarrhoea in children. Rev Infect Dis 1990;12:S51-6.

61 Portnoy BL, DuPont HL, Pruitt D, Abdo JA, Rodriguez JT. Antidiarrhoeal agents in the treatment of acute diarrhoea in children. $\mathcal{F} A M A$ 1976;236:844-6.

62 Diarrhoeal Diseases Study Group (UK). Loperamide in acute diarrhoea in childhood: results of a double blind, placebo controlled multicentre clinical trial. BMf 1984;289: 1263-7.

63 Vesikari T, Isolauri E. A comparative trial of cholestyramine and loperamide for acute diarrhoea in infants treated as outpatients. Acta Paediatr Scand 1985;74:650-4.

64 Bergstrom T, Alestig K, Thoren K, Trollfors B. Symptomatic treatment of acute infectious diarrhoea: loperamide versus placebo in a double-blind trial. F Infection 1986;12: 35-8.

65 Salazar-Lindon E, Sack RB, Chea-Woo E, et al. Early treatment with erythromycin of Campylobacter jejuniassociated dysentery in children. F Pediatr 1986;109:35560

66 Robbins-Brown RM, Mackenjee MK, Bodasing MN, Coovadia HM. Treatment of campylobacter associated enteritis with erythromycin. Am 7 Dis Child 1983;137:282-5.

67 Mandal BK, Ellis ME, Dunbar EM, Whale K. Double-blind placebo-controlled trial of erythromycin in the treatment of clinical Campylobacter infection. $\mathcal{f}$ Antimicrobial Chemotherapy 1984;13:619-23.

68 Pai CH, Gillis F, Tuomanen E, Marks MI. Placebocontrolled double-blind evaluation of trimethoprimsulfamethoxazole treatment of Yersinia enterocolitica gastroenteritis. F Pediatr 1984;104:308-11.

69 Scott DA, Edelman R. Treatment of gastrointestinal nfections. Ballieres Clinical Gastroenterology 1993;7:47799.

70 Nelson JD, Kusmiesz H, Jackson LH, Woodman E. Treatment of salmonella gastroenteritis with ampicillin, amoxycillin, or placebo. Pediatrics 1980;65:1125-30. 